\title{
Design of fractional order controllers using constrained optimization and reference tracking method
}

\author{
Manoj D. Patil ${ }^{1}$, K. Vadirajacharya $^{2}$, Swapnil Khubalkar ${ }^{3}$ \\ ${ }^{1}$ Department of Electrical Engineering, Annasaheb Dange College of Engineering and Technology, Ashta, India \\ ${ }^{2}$ Department of Electrical Engineering, Dr. Babasaheb Ambedkar Technological University, Lonere, Raigad, India \\ ${ }^{3}$ Department of Electrical Engineering, G. H. Raisoni College of Engineering, Nagpur, India
}

\begin{abstract}
Article Info
Article history:

Received Jun 7, 2019

Revised Jul 8, 2019

Accepted Nov 12, 2019

\section{Keywords:}

Constrained optimization

Controller

ABSTRACT

In recent times, fractional order controllers are gaining more interest. There are several fractional order controllers are available in literature. Still, tuning of these controllers is one of the main issues which the control community is facing. In this paper, online tuning of five different fractional order controllers is discussed viz. tilted proportionalintegral-derivative (T-PID) controller, fractional order proportional-integral (FO-PI) controller, fractional order proportional-derivative (FO-PD) controller, fractional order proportional-integral-derivative (FO-PID) controller. A reference tracking method is proposed for tuning of fractional order controllers. First order with dead time (FOWDT) system is used to check feasibility of the control strategy.
\end{abstract}

Fractional order control

Tuning

Corresponding Author:

Manoj D. Patil,

Assistant Professor, ADCET, Ashta, Maharashtra,

Tel: +919763530440

Email: mdpatileps@gmail.com
This is an open access article under the CC BY-SA license.

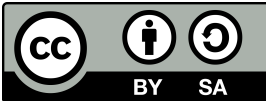

\section{INTRODUCTION}

The proportional-integral-derivative (PID) controllers are broadly used in many industrial applications [1]. The simplicity of structure and easily implementable tuning strategies are behind their success. Many industrial systems can be presented by first order with dead time (FOWDT) models and design of controllers for such systems is important [2]. Ziegler-Nichols tuning, some nature inspired optimization technique like genetic algorithm, particle swarm optimization, ant colony algorithm have widely used techniques for PID controllers [3, 4]. Now-a-days, generalized form of PID controller is getting very popular which is known as fractional order PID (FO-PID) controller [6]. In these controller strategies, integral and differentiators are of fractional order. To use the fractional order is a step closure to real life because the natural processes are mostly fractional [7, 8]. However, the fractional nature may be very small. Clearly, the use of integer order in place of fractional order will differ significantly to the actual situation. However, the integer order models are welcomed due to the absence of solutions to the fractional models. Recently, the fractional order models are analyzed and implemented successfully in $[9,10]$. It is shown that the performance of conventional PID controllers can be improved using the extra degree of freedom from the use of fractional integrator and differentiator [12,13]. Fractional order controllers are being increasingly used for controlling FOWDT systems [14].

Unlike traditional PID controller, the order of integration and/or differentiation in fractional controllers are real and unknown parameters to be tuned. This leads to solving nonlinear equations to design fractional controller. There are different optimization methods are tried to find the parameters of these 
controllers [15]. The conventional tuning rules are not applicable here. A genetic algorithm is proposed for tuning in [16]. Particle swarm optimization is proposed in [17]. In [18], artificial bee colony algorithm is proposed. Some other literature for tuning is reported in $[19,20]$. Still, the area of tuning the fractional order controllers is opened.

In [21], iterative feedback tuning algorithm is employed to tune a type of FO-PID controller. The paper [22] deals with an optimal design of a new type variable coefficient FO-PID controller by using heuristic optimization algorithms. Although many studies have tried to correct the performance of the system's transient and steady state responses. It is obvious that handling the step response and reference tracing together will bring out a better control response. However, there are no studies using different controller parameters of the system with uncertain plant structure. The major contribution of the paper is to fill this gap by presenting a novel approach. In present paper, a reference tracking optimization method is proposed for tuning the fractional controllers. Tuning of different fractional controllers is shown using this method. In the proposed method, even though the controller has changed the optimization algorithm remains same. Only, the controller structure has to be changed. If the plant gets changed, still the reference tracking optimization method works. Hence, the proposed method can provide the solution for tuning of all other fractional controllers.

The organization of the paper is as: some preliminary information is given in Section II. Section III introduces the different controller structures. In Section IV, the tuning methodology is proposed. In Section V, simulation results are given. The paper has been concluded in Section VI.

\section{PRELIMINARIES}

Fractional calculus enables the use of real powers of the integration or differentiation operator. The basics of fractional calculus are described in [23, 24]. Riemann-Liouville (RL) defined the fractional operator as,

$$
{ }_{a} D_{t}^{\alpha} f(t)=\frac{1}{\Gamma(m-\alpha)}\left(\frac{d}{d t}\right)^{m} \int_{a}^{t} \frac{f(\tau)}{(t-\tau)^{\alpha-m+1}} d \tau
$$

where, $(m-1) \leq \alpha<m, \alpha$ is a real number, $m$ is an integer, and $\Gamma($.$) is the Euler's gamma function.$ The Laplace transform of (2) gives,

$$
L\left\{{ }_{a} D_{t}^{ \pm \alpha} f(t)\right\}=s^{ \pm \alpha} F(s)
$$

$s^{ \pm \alpha}$ has to be approximated in integer order for realization. There are several approximation techniques are available [26].

\subsection{Method of Approximation}

Any transfer function can be approximated by interlacing real poles and zeros [27]. The integer order approximation can be obtained within the desired band of frequency by using Oustaloup et al. method [24]. Here, poles and zeros are obtained as follows,

$$
D_{N}(s)=\left(\frac{\omega_{u}}{\omega_{h}}\right)^{\alpha} \Pi_{k=-N}^{N}\left(\frac{1+s / \omega_{k}^{\prime}}{1+s / \omega_{k}}\right)
$$

where, $\omega_{k}=\omega_{b}\left(\frac{\omega_{h}}{\omega_{b}}\right)^{\left.\frac{(k+N+1 / 2+\alpha / 2)}{(2 N+1)}\right)}$ and $\omega_{k^{\prime}}=\omega_{b}\left(\frac{\omega_{h}}{\omega_{b}}\right)^{\left(\frac{k+N+1 / 2-\alpha / 2}{(2 N+1)}\right)}$. The number of poles and zeros are available as $2 \mathrm{~N}+1$, the approximation order is considered as $\mathrm{N}$.

\section{DESIGN OF FRACTIONAL ORDER CONTROLLERS}

Various controller strategies, which are designed based on the fractional calculus, are discussed here.

\subsection{Controller 1. T-PID}

In [23], a different structure of fractional order controller is given, where the proportional term of PID controller is changed with a tilted term with a transfer function $s^{1 / m}$. The new transfer function of T-PID controller closely approximate an optimal transfer function, hence provides improvement in controller. The T-PID controller allows smaller effects of plant parameter variation and better disturbance rejection ratio 
as compared to conventional PID controller. The T-PID controller is obtained as,

$$
u(t)=K_{P} D^{-\alpha} e(t)+K_{I} \int e(t)+K_{D} D e(t)
$$

Applying Laplace transform,

$$
u(s)=K_{P} s^{-\alpha}+K_{I} / s+K_{D} s
$$

where, $K_{P}, K_{D}, K_{I}$ are proportional, derivative, and integral constant, $u(s)$ is control signal, $D$ is derivative operator. The structure of T-PID controller is shown in Figure 1. It shows tilted component with proportional component which is key factor in this controller structure.

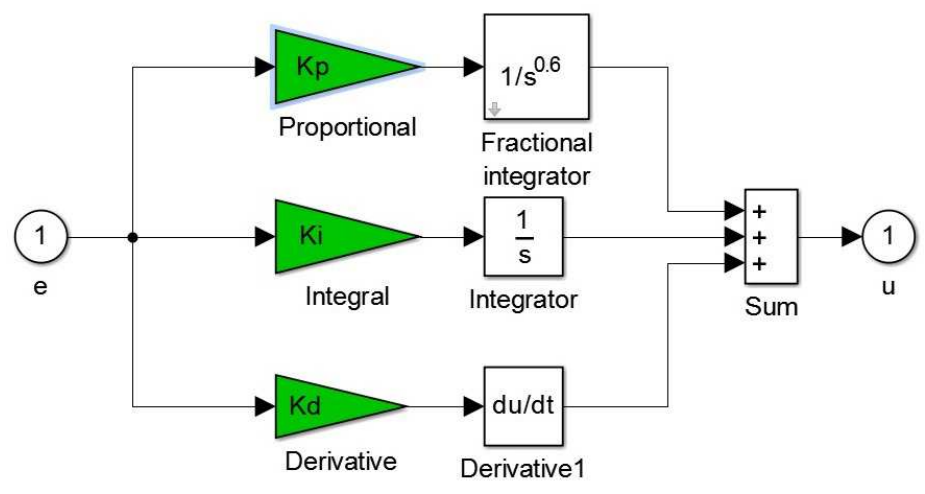

Figure 1. Structure of T-PID controller

\subsection{Controller 2. FO-PID}

FO-PID controller used to minimize the error of the system. The error $e(t)$ is scaled by gain $K_{P}$ in the proportional control. The steady state error is minimized by integral control. The transients in the system are taken care by derivative control. In FO-PID, in addition to $K_{P}, K_{D}$, and $K_{I}$, two more parameters $\alpha$ - integrator order, $\mu$ - order of differentiator are added to give more degree of freedom due to which improvement can be seen in the controller's performance. By adding up all these terms, FO-PID controller is achieved. The FO-PID controller is given by,

$$
u(t)=K_{P} e(t)+K_{I} D^{-\alpha} e(t)+K_{D} D^{\mu} e(t)
$$

Applying Laplace transform,

$$
u(s)=K_{P}+K_{I} s^{-\alpha}+K_{D} s^{\mu},(\alpha, \mu>0)
$$

When $\alpha=1, \mu=1$, PID controller is obtained. When $\alpha=1, \mu=0$, it becomes PI controller. At $\alpha=0$, $\mu=1$, the PD controllers is obtained. The generalization of fractional controllers is shown in Figure 2. It shows the different structures available in the PID domain. FO-PID can be anywhere in the plane. The structure of FO-PID controller is depicted in Figure 3.

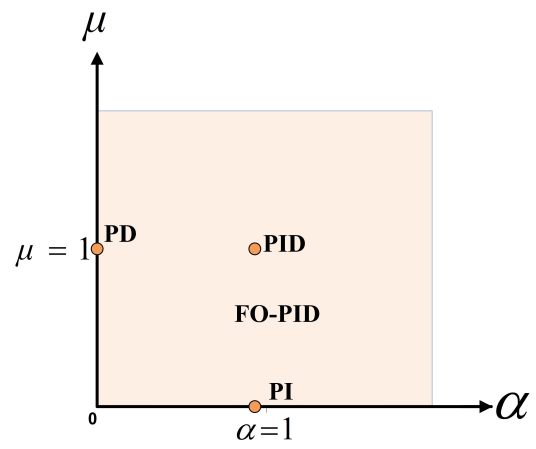

Figure 2. FO-PID generalization

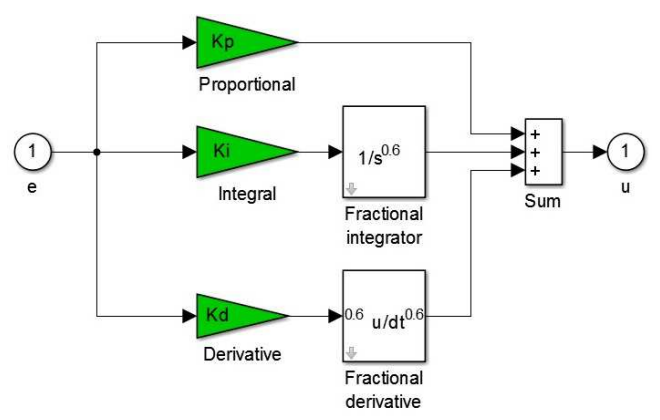

Figure 3. FO-PID controller 


\subsection{Controller 3. FO-PI}

When the $\mu=0$ and $2>\alpha>0$, then the FO-PI controller is obtained as,

$$
u(s)=K_{P}+K_{I} s^{-\alpha}
$$

The FO-PI controller is depicted in Figure 4. The difference is that derivative part is not present, here. If steady state is key issue the FO-PI controller is the best choice.

\subsection{Controller 4. FO-PD}

When the $\alpha=0$ and $2>\mu>0$, then the FO-PD controller is obtained as,

$$
u(s)=K_{P}+K_{D} s^{\mu}
$$

Here, integral part is not in the controller structure. If the plant is having transients then this controller is best choice. The FO-PD controller is depicted in Figure 5.

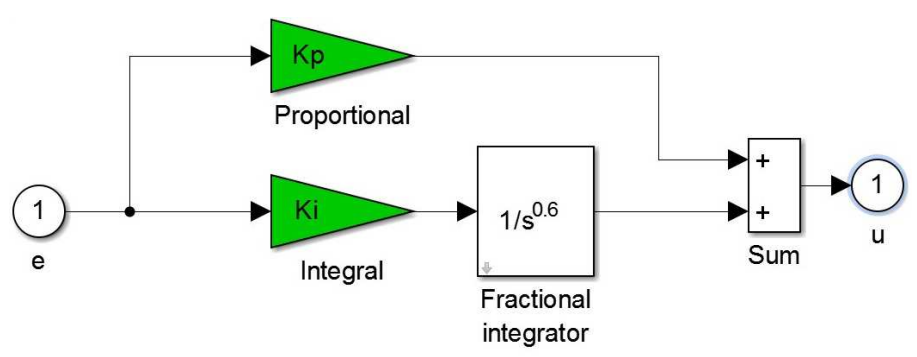

Figure 4. FO-PI controller

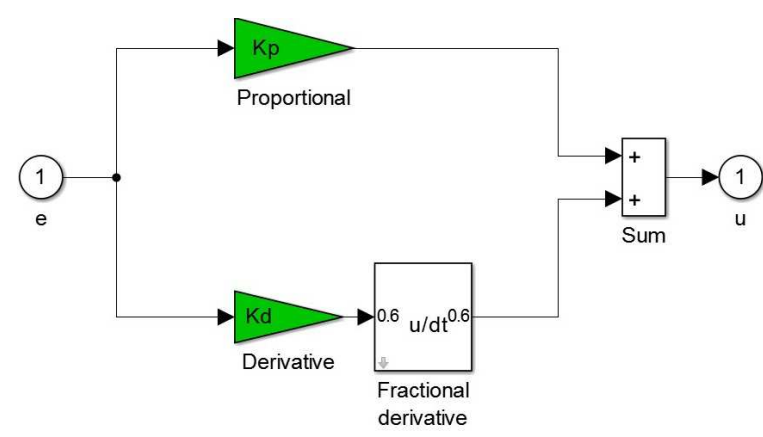

Figure 5. FO-PD controller

\section{PROPOSED TUNING OF THE CONTROLLERS}

Several techniques are available for optimizing the parameters of controllers. Here, constrained optimization method with reference tracking is proposed to optimize the controller parameters. Constrained minimization is the problem of finding a feasible solution that is optimum to a problem subject to constraints. The aim of constrained optimization is to convert the problem into an smaller subproblems which can then be solved by iterative methods. The characteristic of these methods is to translate the constrained problem to unconstrained problem by using an objective function for constraints. In such a way, the solution is found out for constrained problem using a sequence of unconstrained optimizations. The strategy of the simulated model is shown in Figure 6. The constraints are kept on the plant response, including maximum overshoot, settling time, rise time as shown in Figure 7. Also, the reference tracking signal is provided as a goal to be achieved as shown in Figure 8. The model is simulated and the response is checked with initial parameters. The simulation produces an un-optimized step response and the initial data for tuning. The plots are updated so that the design requirements can satisfied. 


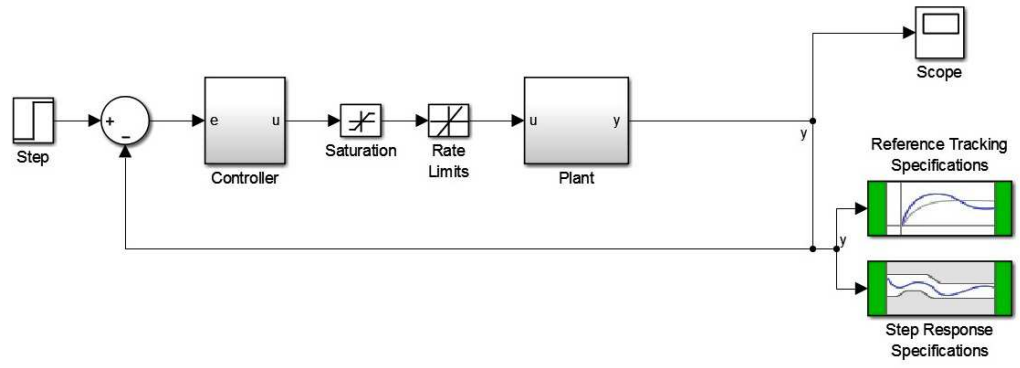

Figure 6. Proposed scheme of optimization process of fractional controllers

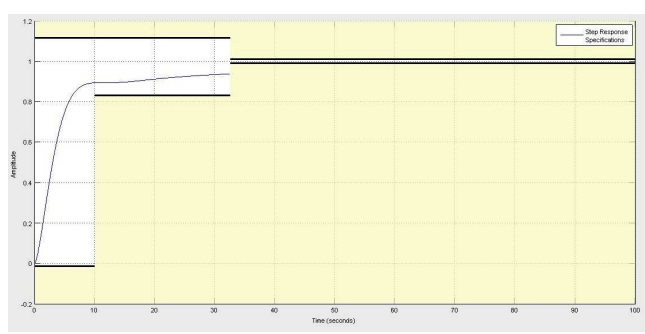

Figure 7. Step response specifications

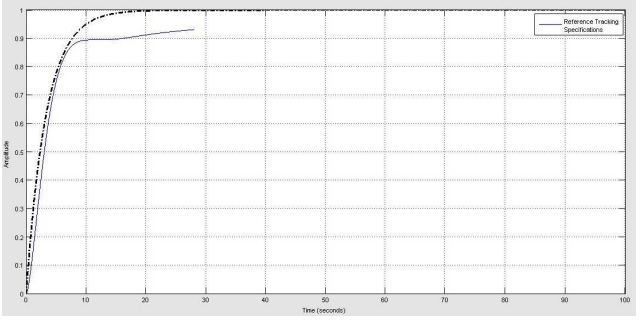

Figure 8. Reference tracking specifications

The optimization algorithm are divided as large and medium scale. The large scale algorithm requires linear algebra that does not store full matrices. This can be done by storing sparse matrices internally. A large-scale algorithm can be used for a small problem. The medium-scale algorithm creates full matrices internally and requires dense linear algebra. If a problem is significantly large, then full matrices require a large amount of memory and a long time to execute. Whereas, a medium-scale algorithm provides extra functionality such as additional constraint types which tends to provide better performance. The guidelines for constrained optimization with reference tracking is as follows:

Step I: Start the process with the use of the 'interior - point' algorithm which is a large-scale algorithm. 'interior - point' not only handles sparse large problems but also a small dense problems. The algorithm satisfies constraints at all iterations, and can recover from ' $I n f / N a N$ ' results. After that go for a different algorithms. The other algorithm may fail, as some algorithms may use more time and memory, while some algorithms may not accept an initial point $[28,29]$. If the problem did not solve then move towards step II.

Step II: In this step, use sequential programming ' $s q p$ ' algorithm should be used. A ' $s q p$ ' algorithm is one of the nonlinear programming methods. ' $s q p$ ' can satisfy bounds at all iterations. The algorithm can recover easily from ' In $\mathrm{f} / \mathrm{NaN}$ '. Here, a quadratic programming subproblem is solved at every major iteration. This method allows constrained optimization [30]. An overview of 'sqp' is found in [31]. If the results are not as per the requirement then go for Step III.

Step III: The 'active - set' algorithm can take large steps that gives speed to the algorithm. The algorithm is effective for problems with nonsmooth constraints. In this method, active constraints are included in canceling operation. These three steps will give the required results.

\section{RESULTS AND DISCUSSION}

Systems with first order plus dead time models have been classified in three categories based on relative dead time $\delta$ which is function of time $T$ and dead time $\tau$ as given below [32]:

1. Lag dominated systems $-\delta<0.1$; where $\delta=\frac{\tau}{\tau+T}$

2. Lag delay balanced systems $-0.1<\delta<0.6$

3. Delay dominated systems $-\delta>0.6$

Here, the results are shown for lag dominated systems only. Whereas, the methodology is tested against lag delay balanced and delay dominated system also. 


\subsection{Case 1. with PID}

The step response specification is shown in Figure 9 and the reference tracking specifications achieved with PID controller is shown in Figure 10. Optimization progress with PID controller is shown in Table 1. The obtained PID parameters are $K_{P}=1.659, K_{I}=0.315, K_{D}=0.173$.

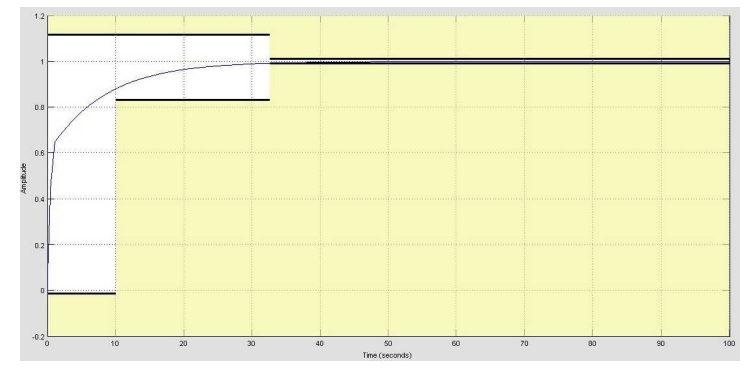

Figure 9. Step response specifications with PID controller

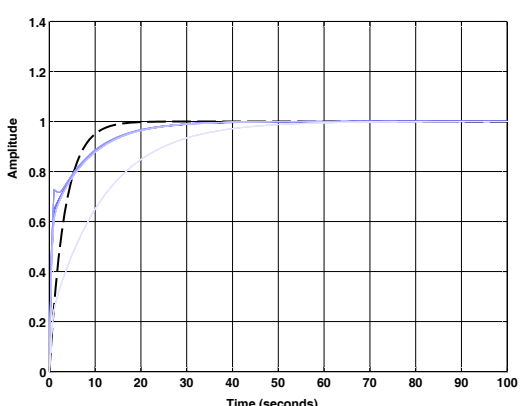

Figure 10. Reference tracking specifications with PID controller

\subsection{Case 2. with T-PID}

Step response specification is shown in Figure 11 whereas reference tracking specifications achieved with T-PID controller is depicted in Figure 16. Optimization progress with T-PID controller is shown in Table 2. The obtained T-PID parameters are $K_{P}=0.2, K_{I}=0.312, K_{D}=1.144, \alpha=0.8$.

Table 1. Optimization Progress with PID Controller

\begin{tabular}{ccccc}
\hline Iteration & $\begin{array}{c}\text { F- } \\
\text { count }\end{array}$ & $\begin{array}{c}\text { Reference Tracking } \\
\text { Specifications } \\
(\text { minimum })\end{array}$ & $\begin{array}{c}\text { Step Response } \\
\text { Specification } \\
(\text { Upper })(<=0)\end{array}$ & $\begin{array}{c}\text { Step Response } \\
\text { Specification } \\
(\text { Lower })(<=0)\end{array}$ \\
\hline 0 & 8 & 217.2816 & -0.0396 & -0.3833 \\
1 & 32 & 51.6097 & -0.0146 & -0.4510 \\
2 & 49 & 50.4433 & -0.0142 & -0.4093 \\
3 & 57 & 14.5348 & -0.0101 & -0.2185 \\
4 & 65 & 6.4976 & -0.0093 & 0.0017 \\
5 & 75 & 5.0369 & -0.0089 & 0.0028 \\
6 & 84 & 3.8441 & -0.0090 & 0.0021 \\
7 & 92 & 3.8441 & -0.0090 & 0.0021 \\
\hline
\end{tabular}

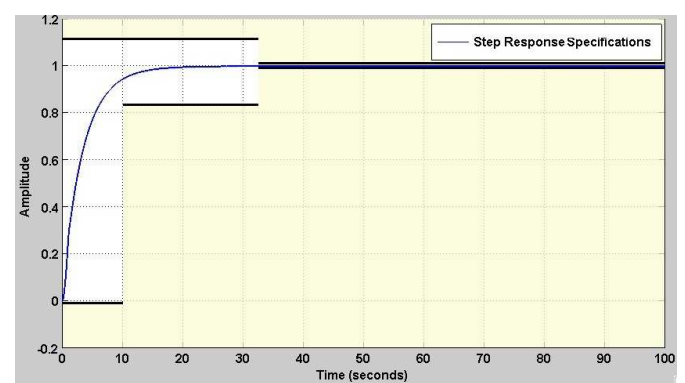

Figure 11. Step response specifications with T-PID controller

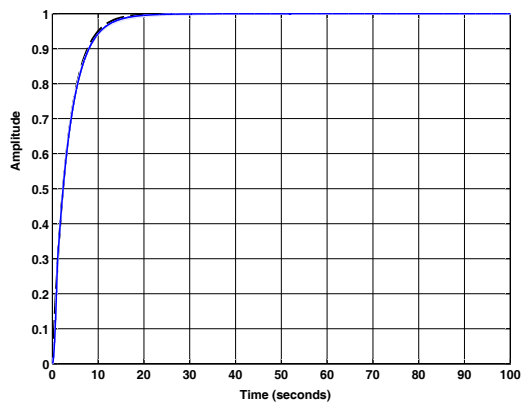

Figure 12. Reference tracking specifications with T-PID controller 
Table 2. Optimization Progress with T-PID Controller

\begin{tabular}{ccccc}
\hline Iteration & $\begin{array}{c}\text { F- } \\
\text { count }\end{array}$ & $\begin{array}{c}\text { Reference Tracking } \\
\text { Specifications } \\
(\text { minimum })\end{array}$ & $\begin{array}{c}\text { Step Response } \\
\text { Specification } \\
\text { (Upper) }(<=0)\end{array}$ & $\begin{array}{c}\text { Step Response } \\
\text { Specification } \\
(\text { Lower })(<=0)\end{array}$ \\
\hline 0 & 8 & 325.7320 & -0.0357 & -0.0521 \\
1 & 32 & 288.3060 & -0.0394 & -0.0493 \\
2 & 46 & 248.7523 & -0.0347 & -0.0344 \\
3 & 54 & 296.1709 & -0.0135 & -0.0015 \\
4 & 62 & 177.7636 & -0.0119 & 0.0018 \\
5 & 76 & 124.0190 & -0.0107 & 0.0062 \\
6 & 94 & 123.9967 & -0.0104 & 0.0076 \\
7 & 104 & 103.6499 & -0.0080 & 0.0105 \\
8 & 112 & 71.6489 & -0.0086 & 0.0103 \\
9 & 121 & 66.5799 & -0.0123 & -0.0012 \\
10 & 129 & 35.0891 & -0.0113 & 0.0030 \\
11 & 137 & 18.5853 & -0.0076 & 0.0105 \\
12 & 145 & 5.1998 & -0.0104 & 0.0069 \\
13 & 153 & 4.0939 & -0.0103 & 0.0075 \\
14 & 161 & 3.8244 & -0.0104 & 0.0071 \\
15 & 169 & 3.6999 & -0.0103 & 0.0074 \\
16 & 180 & 3.5236 & -0.0101 & 0.0089 \\
17 & 199 & 3.5099 & -0.0100 & 0.0091 \\
18 & 211 & 3.5039 & -0.0100 & 0.0092 \\
19 & 223 & 3.5039 & -0.0100 & 0.0092 \\
\hline
\end{tabular}

\subsection{Case 3. with FO-PI}

Step response specification is shown in Figure 13 whereas reference tracking specifications achieved with FO-PI controller is depicted in Figure 14. Optimization progress with FO-PI controller is shown in Table 3. The obtained FO-PI parameters are $K_{P}=1.73, K_{I}=3.49, \alpha=0.55$.

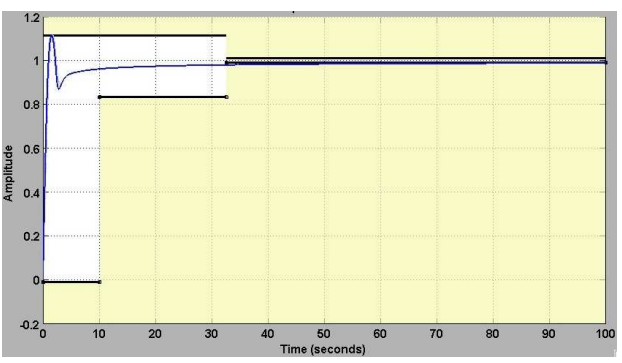

Figure 13. Step response specifications with FO-PI controller

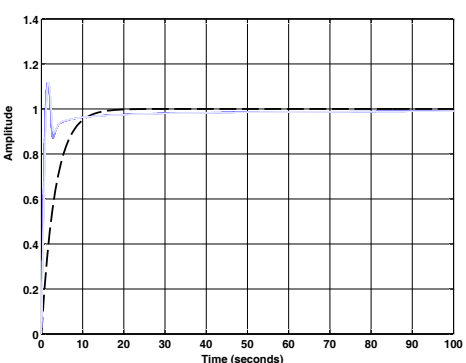

Figure 14. Reference tracking specifications with FO-PI controller

Table 3. Optimization Progress with FO-PI Controller

\begin{tabular}{ccccc}
\hline Iteration & $\begin{array}{c}\text { F- } \\
\text { count }\end{array}$ & $\begin{array}{c}\text { Reference Tracking } \\
\text { Specifications } \\
(\text { minimum })\end{array}$ & $\begin{array}{c}\text { Step Response } \\
\text { Specification } \\
\text { (Upper) }(<=0)\end{array}$ & $\begin{array}{c}\text { Step Response } \\
\text { Specification } \\
\text { (Lower) }(<=0)\end{array}$ \\
\hline 0 & 8 & $3.0496 \mathrm{e}+04$ & -0.4158 & -0.4947 \\
1 & 16 & $6.9294 \mathrm{e}+03$ & -0.1180 & -0.2182 \\
2 & 24 & $2.9033 \mathrm{e}+03$ & -0.0369 & -0.1182 \\
3 & 32 & $1.9057 \mathrm{e}+03$ & -0.0044 & -0.0610 \\
4 & 40 & $1.6598 \mathrm{e}+03$ & 0.0014 & -0.0253 \\
5 & 53 & $1.1243 \mathrm{e}+03$ & -0.0248 & -0.0173 \\
6 & 65 & $1.1886 \mathrm{e}+03$ & -0.0220 & -0.0135 \\
7 & 76 & $1.4792 \mathrm{e}+03$ & 0.0023 & -0.0098 \\
8 & 111 & $1.5002 \mathrm{e}+03$ & 0.0020 & -0.0096 \\
9 & 145 & $1.5214 \mathrm{e}+03$ & 0.0019 & -0.0096 \\
10 & 161 & $1.6484 \mathrm{e}+03$ & 0.0013 & -0.0090 \\
11 & 183 & $1.6540 \mathrm{e}+03$ & 0.0012 & -0.0089 \\
12 & 224 & $1.6540 \mathrm{e}+03$ & 0.0012 & -0.0089 \\
\hline
\end{tabular}




\subsection{Case 4. with FO-PD}

Step response specification is shown in Figure 15 whereas reference tracking specifications achieved with FO-PD controller is shown in Figure 16. Optimization progress with FO-PD controller is shown in Table 4. The obtained FO-PD parameters are $K_{P}=107.8, K_{D}=1.968, \mu=0.63$.

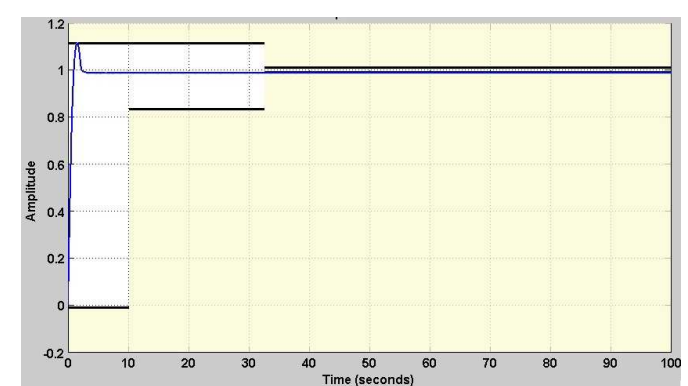

Figure 15. Step response specifications with FO-PD controller

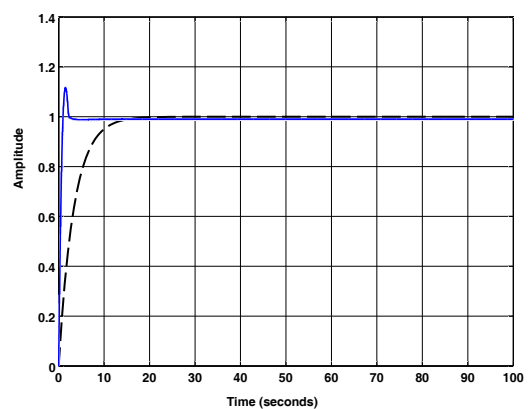

Figure 16. Reference tracking specifications with FO-PD controller

Table 4. Optimization Progress with FO-PD Controller

\begin{tabular}{ccccc}
\hline Iteration & $\begin{array}{c}\text { F- } \\
\text { count }\end{array}$ & $\begin{array}{c}\text { Reference Tracking } \\
\text { Specifications } \\
(\text { minimum })\end{array}$ & $\begin{array}{c}\text { Step Response } \\
\text { Specification } \\
\text { (Upper) }(<=0)\end{array}$ & $\begin{array}{c}\text { Step Response } \\
\text { Specification } \\
\text { (Lower) }(<=0)\end{array}$ \\
\hline 0 & 8 & $4.6123 \mathrm{e}+04$ & -0.5694 & -0.6106 \\
1 & 37 & $4.2841 \mathrm{e}+04$ & -0.5977 & -0.5954 \\
2 & 90 & $4.2834 \mathrm{e}+04$ & -0.5977 & -0.5951 \\
3 & 98 & $1.1651 \mathrm{e}+04$ & -0.1515 & -0.2874 \\
4 & 106 & $4.9829 \mathrm{e}+03$ & 0.0738 & -0.1398 \\
5 & 114 & $2.3560 \mathrm{e}+03$ & 0.0450 & -0.0682 \\
6 & 122 & $2.0831 \mathrm{e}+03$ & 0.0241 & -0.0318 \\
7 & 130 & $2.1208 \mathrm{e}+03$ & 0.0119 & -0.0138 \\
8 & 138 & $2.2145 \mathrm{e}+03$ & 0.0049 & -0.0051 \\
9 & 146 & $2.3234 \mathrm{e}+03$ & 0.0014 & -0.0013 \\
10 & 154 & $2.3443 \mathrm{e}+03$ & $2.4580 \mathrm{e}-04$ & $-1.3125 \mathrm{e}-04$ \\
11 & 162 & $2.3429 \mathrm{e}+03$ & $2.4999 \mathrm{e}-05$ & $-3.0894 \mathrm{e}-06$ \\
12 & 163 & $2.3429 \mathrm{e}+03$ & $2.4999 \mathrm{e}-05$ & $-3.0894 \mathrm{e}-06$ \\
\hline
\end{tabular}

\subsection{Case 5. with FO-PID}

Step response specification is shown in Figure 17 whereas reference tracking specifications achieved with FO-PID controller is shown in Figure 18 . Optimization progress with FO-PID controller is shown in Table 5. The obtained FO-PID parameters are $K_{P}=107.8, K_{I}=0.05, K_{D}=73.9, \alpha=0.51, \mu=0.62$.

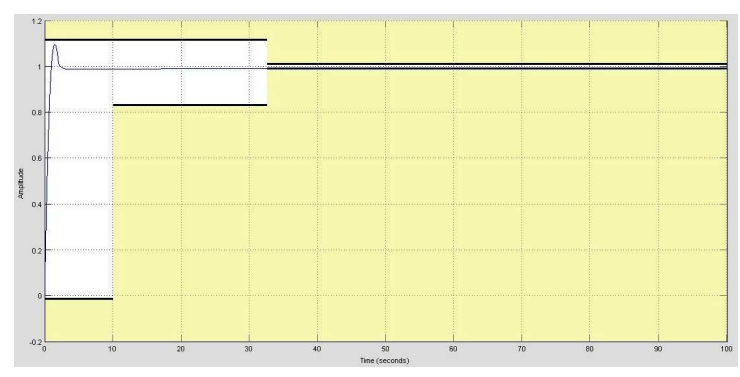

Figure 17. Step response specifications with FO-PID controller

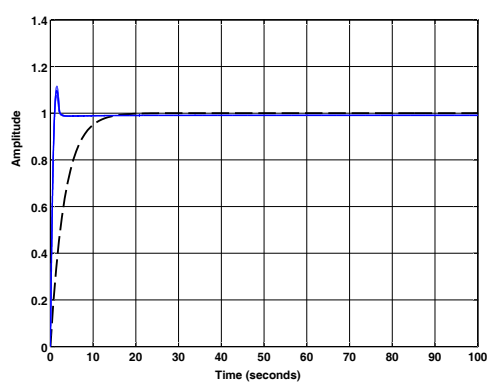

Figure 18. Reference tracking specifications with FO-PID controller 
Table 5. Optimization Progress with FO-PID Controller

\begin{tabular}{ccccc}
\hline Iteration & $\begin{array}{c}\text { F- } \\
\text { count }\end{array}$ & $\begin{array}{c}\text { Reference Tracking } \\
\text { Specifications } \\
\text { (minimum) }\end{array}$ & $\begin{array}{c}\text { Step Response } \\
\text { Specification } \\
\text { (Upper) }(<=0)\end{array}$ & $\begin{array}{c}\text { Step Response } \\
\text { Specification } \\
(\text { Lower })(<=0)\end{array}$ \\
\hline 0 & 8 & $3.3061 \mathrm{e}+04$ & -0.4414 & -0.5273 \\
1 & 16 & $8.4492 \mathrm{e}+03$ & -0.0965 & -0.2408 \\
2 & 24 & $3.6500 \mathrm{e}+03$ & 0.0549 & -0.1193 \\
3 & 32 & $2.1838 \mathrm{e}+03$ & -0.0070 & -0.0522 \\
4 & 40 & $2.0712 \mathrm{e}+03$ & -0.0034 & -0.0240 \\
5 & 48 & $2.1917 \mathrm{e}+03$ & -0.0013 & -0.0099 \\
6 & 56 & $2.3034 \mathrm{e}+03$ & $-6.4314 \mathrm{e}-04$ & -0.0033 \\
7 & 64 & $2.3730 \mathrm{e}+03$ & $-4.5363 \mathrm{e}-05$ & $-6.6447 \mathrm{e}-04$ \\
8 & 72 & $2.3881 \mathrm{e}+03$ & $1.2499 \mathrm{e}-06$ & $-4.1323 \mathrm{e}-05$ \\
9 & 81 & $2.3873 \mathrm{e}+03$ & $1.0911 \mathrm{e}-06$ & $-1.2722 \mathrm{e}-05$ \\
10 & 90 & $2.3855 \mathrm{e}+03$ & $1.2882 \mathrm{e}-06$ & $-3.8773 \mathrm{e}-06$ \\
11 & 91 & $2.3855 \mathrm{e}+03$ & $-3.8773 \mathrm{e}-06$ & $1.2882 \mathrm{e}-06$ \\
\hline
\end{tabular}

Hence, all the available controllers can be tuned with the help of method discussed in this paper. Only the controller structure need to be changed in the simulation and according to constrained and reference tracking method every type of fractional order controller can be optimized. All the five controllers are compared with each other and FO-PID controller is found to be superior in all the five cases. Since, the FO-PID controller is the combination of fractional integrator and differentiator. Fractional differentiator takes care of transient response while fractional integrator looks after the steady state response.

\section{CONCLUSION}

In this paper, different structures of FO-PID controllers are designed and applied to FOWDT process. The tuning methods of fractional controllers involves complex equations. So, it is difficult to find a solution to the problem. Because of that, the tuning method is simplified so that the controller can be tuned very easily and effectively. So that, the constrained optimization algorithm with reference tracking specifications is found to provide solution to tune these controller strategies. The proposed tuning algorithm can be applied to different control strategies and different plant structures.

\section{REFERENCES}

[1] S. Yin, X. Li, H. Gao, and O. Kaynak, "Data-based techniques focused on modern industry: An overview," IEEE Trans. Ind. Electron., vol. 62, no.1, pp.657-667, Jan 2015.

[2] C. Anil and R. Padma Sree, "Tuning of PID controllers for integrating systems using direct synthesis method," ISA Trans., vol. 57, pp. 211-219, 2015. Available: 10.1016/j.isatra.2015.03.002.

[3] A. O'Dwyer, Handbook of PI and PID Controller Tuning Rules. London: Imperial College Press, 2009.

[4] D. Valério and J. da Costa, "Tuning of fractional PID controllers with Ziegler-Nichols-type rules," Signal Process., vol. 86, no. 10, pp. 2771-2784, 2006. Available: 10.1016/j.sigpro.2006.02.020.

[5] T. KACZOREK, Fractional linear systems and electrical circuits. Springer International Pu, 2016.

[6] M. Shamseldin, M. Sallam, A. Bassiuny and A. Ghany, "A novel self-tuning fractional order PID control based on optimal model reference adaptive system," Int. J. Power Electron. Drive Syst., vol. 10, no. 1, p. 230, 2019.

[7] S. Das, Functional Fractional Calculus. Berlin: Springer Berlin, 2014.

[8] K. Sasikala and R. Kumar, "Fractional PID controlled cascaded flyback switched mode power supply with enhanced time domain response," Int. J. Power Electron. Drive Syst., vol. 10, no. 2, p. 909, 2019.

[9] P. Prasad, M. Padma Lalitha and B. Sarvesh, "Fractional order PID controlled cascaded re-boost seven level inverter fed induction motor system with enhanced response," Int. J. Power Electron. Drive Syst., vol. 9, no. 4, p. 1784, 2018. Available: 10.11591/ijpeds.v9.i4.pp1784-1791.

[10] S. Khubalkar, A. Junghare, M. Aware And S. Das, "Modeling and control of a permanent-magnet brushless DC motor drive using a fractional order proportional integral derivative controller," Turkish J. Electrical Engineering \& Computer Sci., vol. 25, pp. 4223-4241, 2017.

[11] R. Verma, N. Pandey and R. Pandey, "Electronically tunable fractional order filter," Arabian J. Sci. Eng., vol. 42, no. 8, pp. 3409-3422, 2017. Available: 10.1007/s13369-017-2500-8.

[12] S. Khubalkar, A. Chopade, A. Junghare, M. Aware and S. Das, "Design and realization of stand-alone digital fractional order PID controller for buck converter fed DC motor," Circ. Syst. Signal Process., vol. 35, no. 6, pp. 2189-2211, 2016. Available: $10.1007 / \mathrm{s} 00034-016-0262-2$. 
[13] A. Chopade, S. Khubalkar, A. Junghare, M. Aware and S. Das, "Design and implementation of digital fractional order PID controller using optimal pole-zero approximation method for magnetic levitation system," IEEE/CAA J. Automatica Sinica, vol. 5, no. 5, pp. 977-989, 2018.

[14] Y. Luo and Y. Chen, "Stabilizing and robust fractional order PI controller synthesis for first order plus time delay systems," Automatica, vol. 48, no. 9, pp. 2159-2167, 2012.

[15] I. Petras, "Tuning and implementation methods for fractional-order controllers," Fractional Calculus Applied Analysis, vol. 15, no. 2, Jan. 2012.

[16] S. Gad, H. Metered, A. Bassuiny, and A. A. Ghany, "Multi objective genetic algorithm fractional order PID controller for semi active magnetorheologically damped seat suspension," J. Vibration Control, vol. 23, no. 8, pp. 1248-1266, 2015.

[17] S. W. Khubalkar, A. S. Junghare, M. V. Aware, A. S. Chopade, and S. Das, "Demonstrative fractional order - PID controller based DC motor drive on digital platform," ISA Trans., vol. 82, pp. 79-93, 2018.

[18] D. Karaboga, B. Gorkemli, C. Ozturk, and N. Karaboga, "A comprehensive survey: artificial bee colony (ABC) algorithm and applications," Artificial Intelligence Review, vol. 42, no. 1, pp. 21-57, Nov. 2012.

[19] S. W. Khubalkar, A. S. Chopade, A. S. Junghare, and M. V. Aware, "Design and tuning of fractional order PID controller for speed control of permanent magnet brushless DC motor," IEEE First International Conference on Control, Measurement and Instrumentation (CMI), 8 Jan 2016, pp. 326-320.

[20] P. Shah and S. Agashe, "Review of fractional PID controller," Mechatronics, vol. 38, pp. 29-41, 2016.

[21] M. R. Estakhrouiyeh, A. Gharaveisi, and M. Vali, "Fractional order proportional integral derivative controller parameter selection based on iterative feedback tuning. Case study: Ball Levitation system," Trans. Inst. Meas. Control, vol. 40, no. 6, pp. 1776-1787, 2017.

[22] O. Aydogdu and M. Korkmaz, "Optimal design of a variable coefficient fractional order PID controller by using heuristic optimization algorithms," Int. J. Adv. Comp. Sci. App., vol. 10, no. 3, 2019.

[23] D. Xue and Y. Chen, "A comparative introduction of four fractional order controllers," In Intelligent Control and Automation, Proceedings of the 4th World Congress on 2002, vol. 4, pp. 3228-3235.

[24] A. Oustaloup, F. Levron, B. Mathieu, and F. Nanot, "Frequency-band complex noninteger differentiator: characterization and synthesis," IEEE Trans. Circ. Syst. I: Funda. Theory Appl., vol. 47, no. 1, pp. 25-39, 2000.

[25] M. V. Aware, A. S. Junghare, S. W. Khubalkar, A. Dhabale, S. Das, and R. Dive, "Design of new practical phase shaping circuit using optimal pole zero interlacing algorithm for fractional order PID controller," Analog Integrated Circ. Signal Proces., vol. 91, no. 1, pp. 131-145, May 2017.

[26] A. M. Lopes and J. T. Machado, "Discrete-time generalized mean fractional order controllers," IFAC Papers OnLine, vol. 51, no. 4, pp. 43-47, 2018.

[27] A. Tepljakov, E. Petlenkov, and J. Belikov, "FOMCON toolbox for modeling, design and implementation of fractionalorder control systems," Appl. Control, pp. 211-236, 2019.

[28] R. H. Byrd, J. C. Gilbert, and J. Nocedal, "A trust region method based on interior point techniques for nonlinear programming," Mathematical Programming, vol. 89, no. 1, pp. 149-185, 2000.

[29] R. Waltz, J. Morales, J. Nocedal, and D. Orban, "An interior algorithm for nonlinear optimization that combines line search and trust region steps," Mathematical Programming, vol. 107, no. 3, pp. 391-408, 2005.

[30] M. J. D. Powell, “A fast algorithm for nonlinearly constrained optimization calculations," Lecture Notes Math. Numerical Ana., pp. 144-157, 1978.

[31] R. Fletcher, Practical methods of optimization. Chichester: John Wiley \& Sons, 2008.

[32] Y. Chen, T. Bhaskaran, and Xue Dingyu, "Practical Tuning Rule Development for Fractional Order Proportional and Integral Controllers," J. Comp. Nonlinear Dynamics, vol. 3, no. 2, p. 021403, 2008.

\section{BIOGRAPHIES OF AUTHORS}

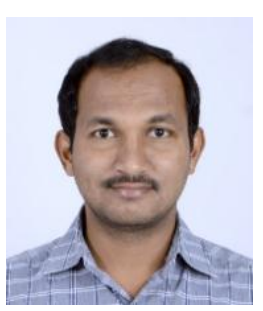

Mr. Manoj D. Patil was born in Sangli, Maharashtra, India, in 1987. He has received his B.E. Degree in Electrical Engineering from Shivaji University Kolhapur, Maharashtra, India in 2009, and the M.E. Degree in Electrical Power Systems from Government College of Engineering Aurangabad (which is affiliated to Dr. Babasaheb Ambedkar Marathwada University Aurangabad), Maharashtra, India in 2011. He is working as Assistant Professor at Annasaheb Dange College of Engineering \& Technology, Ashta, Sangli, Maharashtra since July 2011. He is currently working toward the Ph.D. degree with the Division of Electrical Engineering at Dr. Babasaheb Ambedkar Technological University (BATU), Lonere, Raigad, Maharashtra, India. 


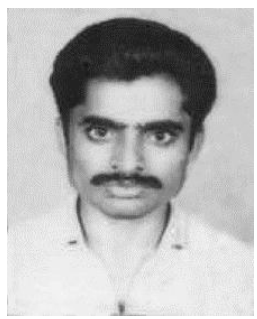

Dr. K. Vadirajacharya received the B.E. degree in Electrical Engineering from PDA College of Engineering, Gulbarga, India, in 1984, the M.E. degree in Power Electronics from GSITS Indore, India, in 1994, and the Ph.D. degree from the Indian Institute of Technology Roorkee, India, in 2009. He has more than 25 publications in different national and international conferences and journals of repute. Currently, he is an Associate Professor in the Department of Electrical Engineering, BATU, Lonere, India. His areas of interest include power quality conditioning, flexible ac transmission device, energy audit, and energy conservation.

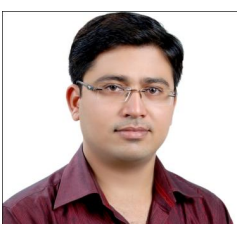

Dr. Swapnil Khubalkar received the B.E. degree in Electronics Engineering in 2010, the M.Tech. degree in Industrial Drives and Control in 2012 from Nagpur University. He received the Ph.D. degree from the Visvesvaraya National Institute of Technology, Nagpur, India, in 2018. He has more than 15 publications in different national and international conferences and journals of repute. Currently, he is an Assistant Professor in the Department of Electrical Engineering, G.H. Raisoni College of Engineering, Nagpur. His areas of interest include Power Electronics, Drives, Fractional order control, etc. 